\title{
Sólo una autobiografía docente
}

Jonathan Alejandro Galindo Soto

$\mathrm{H}$ ace poco, en un Diplomado de Innovación del Aprendizaje, nos solicitaron escribir una autobiografía. Quise empezarla con un análisis reflexivo tan estructurado y casi heroico como el de Miguel Jarquín (2012), con conciencia plena del significado histórico y filosófico de la labor educativa. Hablaría de Ausubel (1983), del plan de implementar los programas de estudio por competencias de la Organización de las Naciones Unidas para la Educación, la Ciencia y la Cultura (UNESCO, 2008), de los retos profesionales en el siglo XXI y cosas así. Pero intento ser honesto. No cínico, sólo honesto.

La verdad es que yo no quería ser profesor. Si bien siempre había sido un alumno incómodo, de esos que contradicen o corrigen al profesor, en licenciatura (en Psicología, por si se lo preguntaba el lector) empecé a conocer a los profesores como personas. Convivía con ellos. Conocí los sindicatos universitarios, las pugnas por presupuestos, el verlos correr desesperados tras puntitos para informes, sus pleitos viscerales disfrazados de laborales. No estaba seguro de qué sería de mi vida laboral (asunto por demás común cuando uno estudia Psicología, dicho sea de paso), pero sí estaba seguro de que jamás daría clases. Jamás andaría sufriendo con tantas responsabilidades y sueldos tan míseros, un empleo por demás ingrato. En eso estaba cuando me di cuenta que terminé la licenciatura y debía trabajar... o seguir estudiando. Así, con todo el ímpetu que mi espíritu dictaba (y la beca), cumplí el deber de todo profesional de seguirse preparando.

Habiendo terminado el doctorado y con cada vez menos opciones de becas, recibí una llamada invitándome a dar clases. Escuché atentamente y repliqué: -¿Pero cuál es el sueldo y el horario?-. La respuesta sonó tentadora y como toda tentación que se respete, me hizo caer. Serían pocas horas. Presentarme ante un grupo -ya lo había ensayado, pues en el posgrado impartíamos ciertas horas, que yo veía como "pláticas"-, dar el tema e irme. Pasa el tiempo, aplico el primer examen. 27 de 29 reprueban. Los miro y pienso: "cada día estamos peor". Estoy seguro que todo lo vimos, se los expliqué, me dijeron que no había dudas, les avisé las temáticas, les proporcioné un libro de texto y hasta resúmenes. Sólo faltó que yo les contestara el examen. Estaba decepcionado. Pésimos alumnos. Platiqué con otros profesores mi desaire y algunos me comentaron que no se podía hacer nada, que así venían desde la primaria.

Todo está perdido. Fingir que educamos y que finjan que nos pagan. En esos momentos recordé a Kundera (2014): "La vida está en otra parte". Ni modo. Pero mis padres (ambos habían dado clase en algún momento) me enseñaron que es más probable que haya un mal maestro a un mal grupo. Repensé mi actuar docente. Quizá era tan simple como que se venía arrastrando un muy bajo nivel educativo y ahora les queríamos exigir demasiado a nivel licenciatura. Bajar las exigencias. Pensé en traer plastilina y muñecos de plástico.

Más adelante, en otra escuela (el salario no permite casi nunca dar clases en una sola institución), se les ocurre asignarme una materia de últimos semestres, en la que los alumnos deberían conjuntar, analizar, aplicar y evaluar el conocimiento y habilidades adquiridos durante su carrera, cosas de Psicología Clínica. Les recordé a los estudiantes su responsabilidad como terapeutas ante pacientes reales, les exigí al máximo. Tuve entonces la peor evaluación de mi carrera docente. Me odiaron. ¿Era entonces asunto de fingir y llevar la fiesta en paz? ¿Exigir poquito y bromear agradablemente? ¿Ser un "profe barco"? La opción sonaba deprimente, pero parecía real. Un callejón sin salida.

$¿$ No he comentado que me encanta ver películas, además de leer? Soy cinépata, diría Fuguet (2012). Recordé a Edward James Olmos en Con ganas de triunfar y a Robin Williams en La sociedad de los poetas muertos. Me animé. Si uno espera poco de los alumnos, dan poco. Si uno espera mucho de los alumnos, debe trabajar con ellos, motivarlos. 
Recordé otras más: Al maestro con cariño, Descubriendo a Forrester, Ni uno menos, Indiferencia, Estrellas en la Tierra, incluso Mentes peligrosas con Michelle Pfeiffer. Pero la que más me sacudió fue El profesor Holland. La película narra la historia de un músico (respeto muchísimo la música, la disfruto, aunque lamentablemente nunca aprendí a tocar ningún instrumento. Desafino cuando toco la puerta). Este hombre, interpretado de forma exquisita por un poco reconocido Richard Dreyfuss, trata de componer, pero no se come de música. La respuesta: si no puedes encontrar trabajo, da clases. Igual que yo, Holland no quería dar clases, sería algo pasajero, en lo que aparece la gran obra. Igual que yo, Holland ve que da su máximo pero los alumnos no dan una; desesperado, les grita y piensa en renunciar. Es cuando recuerda el rock and roll. La música debe disfrutarse para poder aprenderse. Si no se vive, si no se ama, si no se siente lo que se está estudiando, no se aprende nada. Encuentra la motivación que les hacía falta a los jóvenes. Aprende el verdadero sentido de la docencia y el asunto sale bien.

Analicé, entre otros textos, las cinco posibilidades del $\ll$ Si no se vive, si no se ama, si no se siente lo que se está estudiando, no se aprende nada. $\gg$ gistrar. Probé con el aprendizaje significativo de Ausubel (1983), la teoría del desarrollo de Erikson (1987) y el espejo de Lacan (1949). Me di cuenta que antes había mantenido ese ritmo en el que los alumnos ven las clases como una preparación para un examen que les permitiera seguir hacia un futuro empleo aceptablemente remunerado. Había que cambiar nuestra perspectiva. Yo dejaría el falso lugar del docto, para convertirme en un guía acompañante, y ellos se convertirían en constructores de competencias ${ }^{3}$ que les sirvieran de algo en su vida actual, tanto cognitiva como emocionalmente. No se trataba de abandonar el lugar de profesor, sino de disparar el deseo de lectura, de generarles dudas, confusión, emoción. Que se divirtieran aprendiendo, aunque siempre bajo un clima de respeto, compromiso y reglas claras. Algo similar a lo que plantea Watzlawick (2008) cuando recupera el término batesoniano de cismogénesis. ${ }^{4}$

Son adultos jóvenes a los que imparto clases. Eso obliga a generar dinámicas que no estuvieran simplemente copiadas de cuestiones infantiles. No eran la plastilina, los juegos y los muñecos. Había que notar que se encuentran entre la adolescencia y la juventud (Erikson), con las ser docente, y como soy psicólogo, la decisión fue sencilla. ${ }^{1}$ Había navegado entre lo tradicional y autodidacta. Buscaría una respuesta psicológica. Recordé La ola, una de esas cosas raras que se dieron en Stanford en épocas hippies, así como la más famosa "cárcel de Stanford", ambas experiencias llevadas al cine por directores alemanes. $^{2}$ En fin, había que experimentar y re-

1 Fernández y Elortegui (1996): 1) el profesor tradicional/ transmisor, con la idea de que solamente sirve para transmitir un conocimiento ya acabado; 2) el autodidacta/artesano, que desarrolla sus estrategias basado únicamente en su experiencia docente; 3) el tecnológico/por objetivos, que planifica y controla apriorísticamente el proceso de enseñanza-aprendizaje; 4) el empirista/descubridor, que deja al alumno la responsabilidad de descubrir el conocimiento; y 5) el psicologista/constructor, que supone que el proceso debe basarse en el trabajo sobre los esquemas mentales y desarrollo psicológico del alumno.

2 La ola es bastante recomendable, El experimento es buena, pero no tiene mucho que ver con la realidad de lo que hiciera Zimbardo en 1971. Luego saldría una basura hollywoodense con el mismo nombre, en la que se desperdiciaría el talento combinado de Forrest Whitaker y Adrien Brody. crisis de identidad $v s$. confusión y la de intimidad vs. aislamiento. Si pudiera desarrollar un modelo psicopedagógico específico para la licenciatura que retomara esas crisis, podría implicar al alumno al ayudarle a desarrollar una identidad de estudiante. Y aún más, si le ayudamos a que trabaje responsablemente y establezca una relación íntima con ideales y esquemas científicos, cooperaría con su grupo genuinamente. De salir bien el experimento, los estudiantes encontrarían ayuda para responder la pregunta existencial que llevaban años trabajando. El que los modelos teóricos les resultaran desconocidos, permitiría una aproximación más emocionante,

3 Conocimientos, habilidades, valores y actitudes (UNESCO, 2008).

4 Es decir, que hay dos niveles o tipos de interacción comunicativa en el aula. El primero se referiría a interacciones entre pares, entre estudiantes (simétrica) con diferencias situacionales mínimas y contrastantes con el segundo tipo, el de profesor-alumno, cuya interacción (complementaria) está determinada por una diferencia mucho mayor, que no puede en ningún caso ser simétrica. 
pues la idea de un modelo es precisamente dirigir la práctica. Sin embargo, la estrategia debería incluir la crítica al dogmatismo y el escepticismo radical, para evitar que la misma educación formal fomentase "patologías" adolescentes. ${ }^{5}$ Además, debería implicar trabajo de contenidos personales que pudieran ser vinculados con conceptualizaciones, teniendo siempre cuidado de no provocar conflictos subgrupales y de remarcar que los contenidos de sus análisis son confidenciales, sin buscar procesos terapéuticos, manteniendo la información que les parezca demasiado íntima fuera de la discusión grupal para mantener el respeto a la intimidad.

Resumiendo la cuestión lacaniana sobre el espejo, las dinámicas debían basarse en el impacto que les produce a los seres humanos sentir que existen a partir de verse por primera vez en un espejo. Así, la teoría debía reflejarlos, que escribieran sobre ellos mismos, desde los conceptos teóricos. $\mathrm{Su}$ paso por la licenciatura debe servir para que piensen y se piensen como científicos. El asunto salió bien. Actualmente sigo actualizando el modelo, más humanista. Mis evaluaciones salen altas, los alumnos comprenden los contenidos y varios de ellos se acercan solicitando más información. Cambian positivamente después del curso. Aprendí que los alumnos no son cada vez más apáticos o groseros, sino que los docentes hemos caído en un enfoque bajo el cual los contenidos son cada vez más amplios y superespecializados, lo que obliga a la actualización profesional y docente fuera del aula. El problema es que al hacerlo, olvidamos nuestras propias experiencias como humanos (la mayoría en crisis de generatividad), ${ }^{6}$ cayendo en ubicarnos como una autoridad contra la cual es necesario re(v/b)elarse en la adolescencia y juventud, o bien no representamos una figura de respeto con la cual puedan acompañarse para construir amor hacia el estudio y la institución.

Queda claro que no es la única opción, pero hay que empezar por algo. Amo la docencia (pregúntenle a mis alumnos). No lo esperaba, no lo vi

5 Como podrían ser aislamiento, confusión de identidad, egocentrismo, fanatismo y falta de respeto a la intimidad propia y del otro.

6 Buscando trascender en la familia y el trabajo, evitando el estancamiento, el autoritarismo o las regresiones adolescentes.

7 No implica solamente a una pareja, también fidelidad a valores y grupos, a la construcción de ideologías. venir. Son cosas que pasan. Todavía falta incluir blogs, foros, Whatsapp o Facebook, implicarlos más en la retroalimentación posterior al curso con investigación y tesis, fortalecer el trabajo cooperativo fuera del aula y la identidad institucional. En fin, creo que estoy empezando a comprender de qué se trata eso de dar clases. He tomado decenas de cursos de actualización, me retroalimentan mis alumnos, colegas y compañeros de trabajo. Pero nunca dejo de ver películas. Hoy veré Los coristas, parece una buena recomendación. Ya veremos.

\section{Fuentes de consulta}

Ausubel, D., Novak, J. y Hanesian, H. (1968/1983). Psicología educativa: Un punto de vista cognoscitivo. México: Trillas.

Erikson, E. (1963/1987). Chilhood and society. Londres: Collins Publishing Group.

Fernández, J. y Elortegui, N. (1996). Qué piensan los profesores acerca de cómo se debe enseñar. Enseñanza de las Ciencias, 14(3), 331-342.

Fuguet, A. (2012). Cinépata (una bitácora). México: Alfaguara.

Jarquín, M. (2012). Aquellos años de fuego. Persona. Revista Iberoamericana de Personalismo Comunitario. 7(21), 10-13.

Kundera, M. (1969/2014). La vida está en otra parte. España: Tusquets.

Lacan, J. (1949). El estadio del espejo como formador de la función del yo [je] tal como se nos revela en la experiencia psicoanalítica. En Lacan, J. (1966/2013). Escritos 1 (pp. 99-106). México: Siglo XXI.

Organización de las Naciones Unidas para la Educación, la Ciencia y la Cultura. (2008). Estándares de competencias en TIC para docentes. UNESCO. Recuperado el 08 de mayo de 2015 , en: http://bit.ly/2eEg89g.

Watzlawick, P. (2008). Teoría de la comunicación humana. Interacciones, patologías y paradojas. Barcelona: Herder. 